\title{
Autopsia del currículo: En búsqueda de las causas del colapso educativo en tiempos del COVID-19
}

Recibido: 27 de julio de 2021

Revisado: 1 de octubre de 2021 Aprobado: 21 de octubre de 2021

César Toruño Arguedas Costarricense. Doctor en Ciencias

de la Educación, máster en

Planificación Curricular y Administración Educativa. Ha sido asesor nacional en currículum, en el Consejo Nacional de Enseñanza Superior Universitaria Privada (Costa Rica); consultor para el diseño y la evaluación de carreras en la educación superior; profesor universitario, $\mathrm{y}$, actualmente, ejerce funciones en el Programa Exito Académico de la Universidad Técnica Nacional (Costa Rica). Correo electrónico: cesartoruno@gmail.com

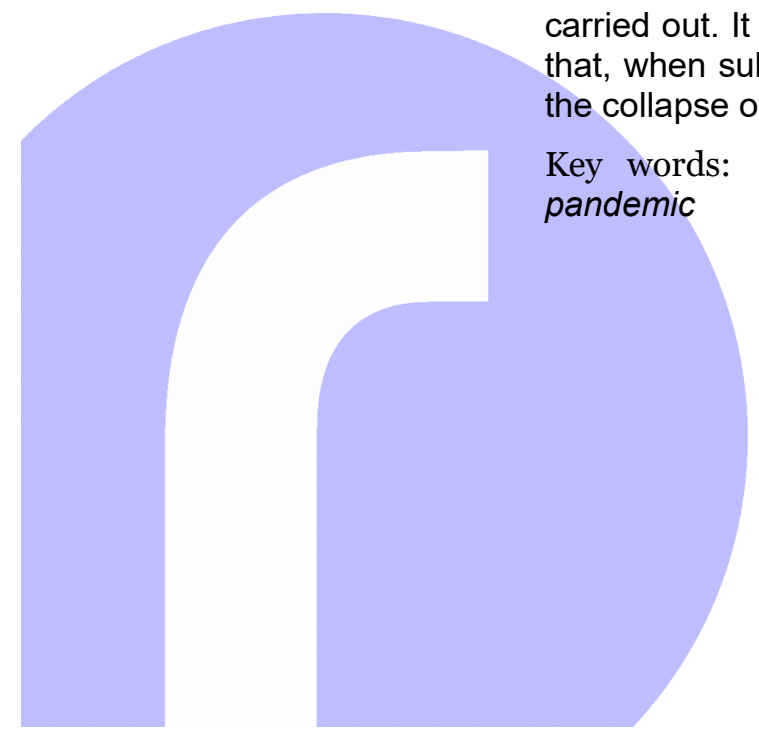

https://revistas.uned.ac.cr/index.php/rupturas (c) (1) (2) (-) pandemia pandemic
Resumen: Las implicaciones del virus SARS-CoV-2 (conocido socialmente como coronavirus o COVID-19) han transformado las realidades sociales, políticas, económicas y culturales a nivel global; esto incluye afectaciones al sistema educativo que, en la mayoría de los países occidentales, ha implicado la suspensión del ciclo lectivo por largos períodos como respuesta ante la incapacidad del sistema para adaptarse a una realidad virtual, según la tesis más aceptada. El presente ensayo sostiene que la incapacidad de adaptación del sistema educativo es producto de una serie de enfermedades latentes en el currículo educativo, motivo por el cual se procede a realizar una autopsia del currículo. Se concluye que el currículo padecía de graves enfermedades que, al ser sometidas al cambio de modalidad presencial a virtual, ocasionaron el colapso del sistema educativo tradicional.

Palabras clave: educación, currículo, pedagogía crítica, currículo crítico,

\section{Curriculum Autopsy: In Search of the Causes of Educational Collapse in COVID-19 Times}

Abstract: The implications of the SARS-CoV-2 virus (known socially as Coronavirus or COVID-19) have transformed social, political, economic, and cultural realities globally; including impacts on the education system which, in most Western countries, has involved the suspension of the school cycle for long periods in response to the system's inability to adapt to a virtual reality; this according to the most accepted thesis. This trial contends that the inability to adapt the educational system is the result of a number of latent diseases in the educational curriculum, which is why an Autopsy of the Curriculum is carried out. It is concluded that the curriculum suffered from serious diseases that, when subjected to the change of face-to-face to virtual modality, caused the collapse of the traditional education system.

Key words: education, curriculum, critical pedagogy, critical curriculum, 


\section{Introducción}

El impacto del COVID-19 (también denominado en el presente ensayo como coronavirus) en el sistema educativo no tiene un referente histórico en la historia de la humanidad. En ningún momento histórico, todos los subsistemas, desde preescolar hasta educación superior de tantos países, habían sido afectados al mismo tiempo y con dimensiones tan abruptas como la suspensión temporal o definitiva de los cursos lectivos.

En este escenario, al establecer la premisa de colapso educativo, este ensayo asume que, por primera vez en la historia pedagógica, los sistemas educativos del mundo se vieron imposibilitados de continuar con sus funciones cotidianas (presencialidad) por períodos determinados (en algunos países, durante meses), al tiempo que fueron sobrepasados por las circunstancias, impidiéndoles ofrecer sistemas de planificación, seguimiento y evaluación de reformas curriculares específicas para la atención de la diversidad de realidades surgidas a raíz de la pandemia.

La imposibilidad de los sistemas educativos para adaptarse a estas circunstancias ha sido analizada desde los retos de la virtualización, principalmente centrados en la formación del profesorado, capacidades de uso por parte del estudiantado y el acceso a equipos o redes de internet. Esta posición es difundida por especialistas, órganos oficiales, medios de comunicación y hasta la propia comunidad educativa; sin embargo, una respuesta tan simple, para un fenómeno tan complejo, conlleva la omisión de problemas estructurales latentes en el sistema educativo.

El presente ensayo asume la hipótesis de que la imposibilidad del sistema educativo para reaccionar ante las circunstancias provocadas por la pandemia se vincula a la muerte del currículo. Es decir, la muerte de un currículo conceptualizado como

el proceso de interacción dialéctica entre un proyecto cultural, económico, político y social que tiene como objetivo la planificación, el control, operacionalización y evaluación de los proceso educativos dirigidos a la transmisión, transformación y construcción de conocimientos, habilidades, destrezas, sensibilidades y actitudes a aprender y desaprender por parte del estudiante para lo cual se estructura una planificación administrativa-pedagógica y financiera así como una organización del poder, del espacio y el tiempo educativo junto a la distribución de conoci- 
mientos por áreas, asignaturas o especialidades, el diseño de un programa de estudio (producto tangible de la selección y organización de contenidos), mediaciones didácticas, actividades vivenciales fuera del aula y la evaluación; y la realidad de la operacionalización de dicho proyecto en el entramado educativo, mediado por las subjetividades, acciones e inacciones de tomadores de decisión a nivel político, mandos medios y docentes, así como la resistencia, consciente o inconsciente, de docentes, estudiantes y sus familias que favorecen la creación de un currículum real diferente al currículum diseñado o esperado (Toruño 2020, 52-53).

Por lo anterior, se procederá a realizar una autopsia del cadáver curricular para determinar las enfermedades que poseía y que pudieron provocar su muerte, esto a partir de la premisa de que resulta necesario "discutir o investigar sobre el currículum supone tocar algo visible y encarnado socialmente. Necesitamos apoyarnos en un enfoque más holístico, complejo y estimulante superando las disquisiciones burocráticas sobre el plan de estudios, el cuestionario el programa escolar" (Gimeno 2010, 42).

La autopsia aquí realizada analiza un sujeto (currículo) con características comunes para Costa Rica, Latinoamérica y, probablemente, Iberoamérica; con un margen de cobertura desde preescolar hasta educación superior, se utiliza lenguaje médico para contextualizar la narración sin intención de profundizar sobre las situaciones de salud y reconociendo que el expediente del paciente reporta un estudio médico por parte del Dr. Abrahamson (1978), el cual es un antecedente del estado de salud en el que solo existe coincidencia en la denominación de la artritis curricular, por cuanto se describen nuevas enfermedades con sus respectivas concepciones.

\section{Antecedentes médicos curriculares del sujeto}

Ante nosotros yace el cuerpo de Currículo, con una edad aproximada de 102 años desde que John Franklin Bobbitt propuso la primera sistematización del currículo. A pesar de su avanzada edad, se consideraba un individuo con buena salud gracias a su condición genética (enfoque técnico) y a sus hábitos de vida pedagógica saludable (enfoque práctico).

La condición genética del currículo está marcada por un ADN de enfoque técnico caracterizado por elementos como el control, la planificación, la asimilación de las personas como objetos que acumulan aprendizajes y la vincula- 
ción con la producción propias de una Pedagogía por Objetivos (Gimeno, 1997). Este ADN se caracteriza por los cromosomas TyT de Tyler (1973) y Taba (1974), el cual define las características estructurales del currículo compuesto por un diagnóstico de necesidades, la definición de objetivos, el uso de fundamentos (principalmente psicológicos y disciplinares), selección y organización de contenidos, planificación de actividades didácticas y una prestablecida evaluación.

El enfoque curricular técnico provocó una rigidez al sujeto curricular entre 1950 y 1970. La extrapolación de una visión empresarial le sometió a una presión para controlar y fragmentar todo el proceso educativo (división por años, ciclos, asignaturas, pruebas estandarizadas para verificar la calidad del "producto", certificaciones, entre otros). Sin embargo, en este período, la principal enfermedad del sujeto curricular fue la reducción de la innovación-libertad pedagógica (simplificación técnica de la labor docente para ser un aplicador de técnicas didácticas) y de la persona estudiante, esta última caricaturizada como un objeto vacío al que se debía llenar de información, valores, pensamientos y competencias.

Es claro que la condición genética del currículo resultaba inviable con su propia existencia en la segunda mitad del siglo XX. Un mundo en plena revolución tecnológica, con movimientos sociales y culturales que exigían transformaciones socioeconómicas y con cambios en el sistema productivo, habría provocado la muerte de cualquier sujeto con un ADN que apostaba por la rigidez epistémica, metodológica y evaluativa. En este contexto, 1970-2000, el currículo adquiere una serie de hábitos de vida pedagógica saludable con la incorporación de principios diluidos de constructivismo (con pequeñas dosis de socioconstructivismo) y la incorporación de vitaminas S y S para la constitución de un enfoque práctico, es decir, aportes de Schwab y Stenhouse.

Las vitaminas del enfoque práctico permitieron adaptar el currículo con especial atención de los aportes energéticos de Stenhouse (2003), estos últimos posibilitaron la incorporación de demandas sociales con currículo de principios abierto a discusión, no centrado en objetivos, sino en el proceso, espacio de investigación y evaluado con técnicas más amplias. Con estas vitaminas, el currículo adquiere una nueva dimensión epistémica (constructivista), metodológica (aprendizaje basado en problemas, talleres, resolución de problemas, investigaciones, etc.) y concibe un nuevo rol para docentes (investigadores y creadores de currículo) y estudiantes (participantes activos de la creación-transformación de aprendizajes).

No obstante, a pesar del ingreso de las vitaminas del enfoque curricular práctico, entre 1970 y la actualidad, el sujeto curricular ha sufrido un debilitamiento de su condición de salud provocado, en primer lugar, por el mantenimiento de la contextualización curricular técnica (docente aplicador de técnicas, verticalismo del poder, estudiante considerado como objeto vacío y evaluaciones sumativas), cuya cultura organizacional ha sido dominante en los centros educativos. En segundo lugar, las crisis económicas mundiales (finales de 1970, 2008 y pandémica) y locales (propias de cada país o regiones en occi- 
dente) aunado al ascenso del neoliberalismo en Occidente, repercutieron en recortes en infraestructura, equipos y programas de equidad, lo cual degeneró en círculos viciosos que afectaron la calidad educativa en áreas académicas, convivencia, competencias y hasta en la función misma de la educación pública.

En tercer, y último lugar, los cambios productivos-tecnológicos y culturales vividos a finales del siglo XX e inicios del siglo XXI marcaron una ruptura histórica entre el sistema educativo, la vivencia educativa y las realidades contextuales del centro educativo. Por primera vez, el personal docente está claramente formado bajo preceptos metodológicos y epistemológicos del siglo anterior, estudiantes y familias están en realidades de convivencia y aprendizaje propios del siglo XXI; tanto que los centros educativos y la estructura curricular son sobrepasados por cambios culturales y tecnológicos mucho más rápidos que las capacidades institucionales para analizar y actuar.

Por lo anterior, se puede afirmar que, durante las últimas décadas, el currículo incorporó tatuajes como signos de cambio y modernización, desde nuevas teorías epistémicas (complejidad), mediaciones como aula invertida, exploración, lúdicas y plataformas tecnológicas, hasta la inclusión de nuevos instrumentos de evaluación cuantitativa y la utilización de la evaluación cualitativa. A nivel teórico, se incorporan nuevas tendencias curriculares, pero se mantuvo alejado de la pedagogía crítica y el enfoque crítico (Toruño, 2020) como transformadores del diseño curricular, la vivencia del aprendizaje y la función del sistema educativo.

\section{Causas de muerte}

El paciente ha sufrido un fuerte traumatismo al pasar de la presencialidad a la virtualidad; sin embargo, no existe evidencia de que este sea la causa de su muerte por lo que se procede con una autopsia cuyos resultados no son concluyentes. A continuación, se identifican el accidente cerebrocurricular, el infarto al miocardio (aprendizaje), el cáncer linfático (con especial atención de los linfocitos docentes), la cirrosis evaluativa, la artritis curricular, las cirugías estéticas, los problemas psiquiátricos, el uso de esteroides pedagógicos y una mala praxis como posibles causas de la muerte.

\section{Factor ambiental}

Antes de proceder con la descripción de las posibles causas de muerte, y a pesar de no ser el objetivo del presente ensayo, esta autopsia no puede omitir el factor ambiental en la muerte del sujeto curricular.

Durante los últimos años, principalmente desde finales de 1970, el currículo occidental fue sometido a un estrés ambiental provocado por el dominio de corrientes capitalistas-neoliberales (con excepción de ciertos países con modelos socialistas o socialistas del siglo XXI cuya operacionalización implicó otra propuesta curricular no exenta de cuestionamientos pedagógicos y es- 
trés ambiental). Las corrientes neoliberales realizaron ajustes neoliberales (Toruño, 2010), y sus principios exigieron recortes en el mal denominado "gasto educativo".

El estrés ambiental provocado por los recortes se manifestó en una reducción de puestos disponibles, deterioro de la infraestructura y equipo educativo, aumento de la tasa de estudiantes por grupo, deterioro de los perfiles de selección docente, aumento en los indicadores de exclusión, menor inversión en programas de equidad, aumento de contenidos-competencias por desarrollar (sobrecarga de planes de estudios), cierre de especialidades consideradas no relevantes para el modelo productivo, la inclusión de pruebas estandarizadas para medir el rendimiento con una clara propuesta de selección darwinista educativa, entre otros elementos materiales, epistemológicos, metodológicos y de contextualización curricular.

Es importante comprender que el factor ambiental fue determinante en el deterioro de la salud curricular del sujeto al que hoy se aplica esta autopsia educativa, por lo que se requieren estudios propios para establecer las correlaciones entre las medidas neoliberales y el surgimiento de las enfermedades aquí descritas.

\section{Accidente cerebrocurricular}

El paciente presenta un accidente cerebrocurricular en su área de conocimiento, ya que como especialidad pedagógica que "investiga, analiza y sistematiza el conocimiento sobre diseño, operacionalización, evaluación y mejora de los procesos educativos dirigidos a la transmisión, reproducción, transformación y construcción de saberes, habilidades, destrezas, sensibilidades y actitudes en el marco de la educación formal" (Toruño 2020, 52) ha sufrido una trombosis múltiple con coágulos de falsos curriculistas (certificados, pero sin pensamiento curricular), disminución de presupuestos para investigación curricular, aislamiento de investigadores curriculares, disminución de la producción científica desde América Latina, desvirtualización de los aportes de la escuela española, alejamiento de las corrientes de la sociología de la educación, simplificación del diseño curricular a la formulación aislada y descontextualizada del currículo, sobredimensión de lo didáctico, constitución de los centros educativos como maquilas académicas y reducción de los docentes a técnicos especialistas.

Este paciente habría tenido una mejora en la resistencia de su apartado cognitivo-cerebral si hubiese practicado la pedagogía crítica y el enfoque curricular crítico, asumiéndose como "un territorio controvertido y hasta conflictivo, respecto del cual se toman decisiones, se siguen opciones y se actúa por orientaciones que no son las únicas posibles" (Gimeno 2010a, 29), trastocado por un currículo oculto (Torres, 1998) y por un Estado en conjunción con grupos dominantes le utilizan para "producir, reproducir, distribuir y cambiar los recursos simbólicos, la 
conciencia misma de la sociedad" (Apple 1996b, 86) con especial acento en la formación de un conocimiento oficial construido desde una hegemonía (Apple 1996a) dentro de un proyecto neoliberal (Torres 2007) y global descrito perfectamente bajo la metáfora de las patatas fritas (Apple 1997).

Asumir que "las escuelas no son ideológicamente inocentes" (Giroux 2006, 205) y que el currículo (y, por ende, el sistema educativo) "se produce a partir de conflictos, tensiones y compromisos culturales, políticos y económicos que organizan y desorganizan un pueblo" (Apple 1999, 153) habría permitido el cuestionamiento del currículo nacional (desde preescolar hasta la educación diversificada), la ineficacia de las reformas impulsadas durante las últimas décadas, el dilema del impulso de formación para el trabajo, los problemas estructurales latentes de las realidades de la contextualización curricular, función docente y papel de la población estudiantil y las posibilidades de cambio-transformación del sistema. Estos debates eran relevantes previo a la pandemia y adquieren más importancia dada la evidente paralización del sistema educativo.

Se puede concluir que el accidente cerebrovascular del currículo provocó una paralización general del paciente previo al fallo sistémico que provocaría su muerte. Así mismo, mayores ejercicios progresistas y la pedagogía crítica pudieron revitalizar el currículo y disminuir el riesgo de trombosis; al respecto, las premisas de Freire (2001) habrían motivado la constitución de diseñadores curriculares con un pensamiento crítico del mundo, apegados a una utopía de acción y el compromiso de ruptura con injusticias (pedagógicas, sociales, económicas y culturales), la transformación de las relaciones y la motivación constante para la intervención en el mundo.

\section{Infarto al miocardio}

El sistema cardiovascular del currículo es la parte esencial del currículo comprendido como proceso. Se encarga de "la transformación del programa de estudio en contenidos para enseñar o para aprender, se centra en la contextualización curricular y las actividades didácticas-evaluativas implementadas en el aula" (Toruño 2020, 54) por lo que el corazón de este complejo sistema es el proceso de aprendizaje realizado en la contextualización curricular en concordancia del currículo oculto (Torres 1998), como producto, procesado, práctica educativa e inesperado (Toruño 2020).

Durante las últimas décadas, el sistema cardiovascular del currículo se ha encontrado con el aumento de contenidos innecesarios y de poco valor pedagógico, cuyos restos se han acumulado en los planes de estudio, formando placas de grasa que obstruyeron las arterias del sistema y provocaron un infarto al miocardio.

Junto a las obstrucciones en las arterias, es palpable una ateroesclerosis, es decir, un endurecimiento de las arterias del corazón curricular 
vinculadas con la mediación docente, en el tanto la excesiva carga de contenidos "acabó por desviar las miradas del profesorado, casi exclusivamente a las cuestiones metodológicas (en el mejor de los casos) y de evaluación y de vigilancia disciplinaria del alumnado" (Torres 2006, 56).

Este énfasis en lo didáctico condujo, durante las últimas décadas, a que el currículo cambiase sus hábitos alimenticios vinculados con el conductismo a la vida saludable del constructivismo. Sin embargo, la nueva alimentación se caracterizó por ser baja en metodologías sustantivas y verdadera asimilación por parte de los linfocitos (docentes) del sistema. Como bien afirma Torres (2007, 181), "una vez que el positivismo y los modelos conductuales estén siendo objeto de ataques contundentes, comienza a entrar a escena un constructivismo un tanto descafeinado, en numerosas ocasionas releído desde posiciones psicológicas conservadoras" (Torres 2007, 181), incluso Torres (2007, 182) describe con mayor detalle este mal al indicar:

Muchas personas únicamente se quedan con una idea un tanto abstracta de que todo es cuestión de "construcción", pero de una manera tan vacía que, en los momentos de la acción práctica, muchos profesores y profesoras se sienten incapaces de trasladar esa filosofía a las situaciones reales con las que se tienen que enfrentar en sus aulas.

Aunado a lo anterior, el expediente demuestra que el paciente padecía de una presión alta causada por el desarrollo magisterial y, en general, de

una delicada encrucijada, viviendo una tensión inevitable y preocupante entre las exigencias de un contexto social móvil, cambiante, flexible e incierto, caracterizado por la complejidad tecnológica, la pluralidad cultural y la dependencia de los movimientos del libre mercado mundial por un lado y las rutinas, convenciones y costumbres estáticas y monolíticas de un sistema escolar inflexible, opaco y burocrático por otro (Pérez 1998, 163).

La presión alta generó constantes dolores de cabeza en el cerebro curricular, mareos y sudoración vinculadas con el surgimiento de constantes, poco reflexivas y poco relevantes reformas curriculares; manifestaciones que alertaban 
de la débil condición del paciente para enfrentar un momento de estrés extremo, como una transición abrupta de la presencialidad a la virtualidad.

La obstrucción de las arterias pedagógicas con contenidos innecesarios, la presión alta y el endurecimiento de las arterias provocado por décadas de consumo de conductismo y las últimas décadas de alimentación basada en constructivismo descafeinado provocaron un debilitamiento sistemático del corazón hasta que, en el escenario de trasladar la contextualización curricular a la virtualización, el corazón curricular (los aprendizajes) no soportó la transformación y, por ende, el paciente sufrió un infarto al miocardio curricular del aprendizaje.

\section{Cáncer linfático}

El currículo posee un sistema inmunológico para la defensa de su existencia (el currículo existe en tanto tenga una función de aprendizaje para estudiantes y docentes) compuesto, esencialmente, por linfocitos $D$ (docentes), linfocitos $E$ (estudiantes) y linfocitos $O$ (comunidad, familia y personal de los centros educativos).

Enfermedades como la reformitis aguda, la politiquería pedagógica, la didáctica excesiva, el consumo de materiales didácticos trans (libros de textos), el consumo de energía vital en papeleo y acciones administrativas, exclusión escolar, bajo rendimiento, acoso escolar y hasta fenómenos de contexto sociocultural podrían haber sido detenidas o al menos mermadas con un sistema inmunológico fortalecido en la contextualización curricular.

El paciente presenta un extendido cáncer linfático de desmotivación que ha afectado la generación de linfocitos $D$ (Docentes). La desmotivación docente es causada, según Torres (2006), por la incomprensión de las finalidades de los sistemas educativos, formación inicial deficitaria, pobreza de las políticas de actualización del profesorado, concepción tecnocrática del trabajo docente, un currículo obligatorio sobrecargado de contenidos, una administración del sistema educativo burocratizante, falta de servicios de apoyo y de una inspección escolar, ausencia de una cultura democrática en los centros educativos, problemas de comunicación con el alumnado, dificultades para relacionarse con las familias, el profesorado como único responsable de la calidad de la educación, ambiente social de escepticismo y banalización, políticas de mercantilización y privatización, falta de incentivos al profesorado más innovador, una continua ampliación de las funciones encomendadas a la educación y mayor visibilidad de los efectos del trabajo del profesorado.

También se encuentra que el sistema inmunitario del paciente tiene minúsculos grupos de linfocitos $D$, al parecer reflejo de una enfermedad de Perniciosa Cultura Escolar "vinculado al sentido patrimonialista de su aula y su trabajo" 
(Pérez 1998, 166), que provoca un aislamiento psicológico, ecológico (condiciones físicas y administrativas) y aislamiento adaptativo, así como una competitividad y balcanización (Pérez 1998, 168) con especial énfasis en asignaturas.

Los buenos linfocitos que aún resistían en el cuerpo curricular sufrían el dilema de:

un profesorado que se siente amenazado, real o imaginariamente, en los centros, y cuyas miradas y líneas de actuación están muy interesadas en buscar fórmulas para escapar de las aulas, es bastante probable que no sea sino el síntoma de un sistema educativo cuyos profesionales no lo acaban de comprender, para el que no se sienten preparados y en el que las políticas vigentes y las condiciones materiales de los centros dejan mucho que desear (Torres 2006, p. 111).

Las manifestaciones del cáncer de la desmotivación eran evidentes en el cuerpo curricular. El público en general lo veía cansado, inútil, innecesario y hasta superado; sus enemigos empresariales demandaban trasplantes urgentes para el fortalecimiento de Competencias y Emprendurismo, sus aliados progresistas le defendían describiendo la tierra prometida de un futuro de significatividad, aprendizajes, relevancia y transformación para la cual irónicamente tendría que cumplir el destino de Moisés (andar en el desierto para morir a las puertas de la tan ansiada tierra), y los políticos de turno promovían una invasiva quimioterapia para extraer a todos los linfocitos para, según su absurda teoría, matar al cáncer eliminando los linfocitos.

Con la pandemia del coronavirus, el sistema educativo demandó al currículo un rápido traslado de la presencialidad a la virtualidad para lo cual no tenía linfocitos $D$ suficientemente preparados, fortalecidos y capacitados para la nueva realidad. Por el contrario, los linfocitos $D$ sufrieron el agobio de los nuevos requisitos, mientras que "uno de los sentimientos más constantes del profesorado en la actualidad es su sensación de agobio, de saturación de tareas y responsabilidades para hacer frente a las nuevas exigencias curriculares y sociales que presionan la vida diaria de la escuela" (Pérez 1998, 166).

Con un cáncer de desmotivación, una disminuida producción de glóbulos blancos y el agobio generalizado, la virtualidad era un escenario mortal para el currículo. Al trasladarse al nuevo escenario las enfermedades de la contextualización curricular virtual, el currículo presenció la reproducción de nuevas enfermedades (limitaciones en equipo y acceso a redes de internet, atención disminuida en clases virtuales y la reaparición del conductismo en su versión 
4.0). Así mismo, es probable que el cáncer encontrado tenga relación con la cirrosis evaluativa que se analizará a continuación.

\section{Cirrosis evaluativa}

El sistema digestivo curricular se encuentra integrado por el estómago (programas de estudio de cursos o asignaturas), el páncreas (procesos de evaluación estudiantil a nivel comunal, regional o nacional), los intestinos (evaluación institucional que regula la digestión y la producción de hormonas para fortalecer determinados apartados curriculares), y el hígado/vesícula que cumplen una función crucial para la evaluación de los aprendizajes, ya que la vesícula genera los componentes para digerir los contenidos y el hígado integra los instrumentos-prácticas evaluativas de la contextualización curricular para regular los niveles de aprendizajes en todo el sistema cardiovascular.

Se encuentra que el paciente padecía de una cirrosis evaluativa caracterizada por una cicatrización y endurecimiento de la evaluación de los aprendizajes en la contextualización curricular. Esta cirrosis es producto de una enfermedad crónica por la adicción del paciente al consumo de evaluaciones conductistas, instrumentos homogeneizantes y masificados, importación de técnicas, sobrevaloración de lo cuantitativo, constitución de maquilas evaluativas, ausencia de reflexión docente sobre el papel evaluativo y los intereses ocultos (docentes, políticos, del sistema y de grupos de presión) para generar una discriminación académica teñida con colores de objetividad.

Los síntomas de la enfermedad habían sido descritos por Santos Guerra (1995), quien estableció que las principales patologías que afectan a la evaluación son evaluar únicamente al alumno, solo los resultados, solo los conocimientos, los resultados directos (pretendidos), exclusivamente los efectos observables, solo la vertiente negativa, solo a las personas, de forma descontextualizada, cuantitativamente, con instrumentos inadecuados, de manera competitiva y estereotipadamente, para controlar, para conservar, unidireccionalmente, desde fuera, sin autoevaluación, sin paraevaluación (evaluar más allá de descripción y análisis del programa) y sin metaevaluación.

Aunque la cirrosis era crítica, de esta autopsia no se pueden omitir los daños generalizados en el sistema digestivo-evaluativo, destacando las úlceras y gastritis del estómago (programas) provocado por el consumo excesivo de contenidos y actividades didácticas insalubres, una pancreatitis crónica causada por la inflamación de las pruebas para la selección y aprobación estudiantil (cuya consecuencia directa ha sido que el páncreas comience a digerirse así mismo) y daños en las funciones de intestinos (evaluación institucional) con manifestaciones de obstrucciones e inflamaciones, las cuales provocaron constantes dolores e incomodidades al paciente. 


\section{Artritis curricular}

El paciente presenta una artritis curricular, es decir, una afectación en las articulaciones que le impedían mover sus extremidades, en el nivel actual de la enfermedad, le era imposible caminar al ritmo de los cambios socioculturales, políticos y económicos e, igualmente, era inviable que pudiese sostener con sus manos cualquier instrumento de cambio.

En este caso específico, la artritis inició como un proceso de la pedagogía por objetivos (Gimeno, 1997), vinculado al surgimiento del currículo al iniciar el siglo XX, es decir, la extrapolación de mecanismos industriales, empresariales y económicos a la educación, su organización, implementación y evaluación. Con el paso de las décadas, se desarrolló un afán por el tecnicismo en el diseño y en la didáctica, por el control del proceso y del aprendizaje y la constante evaluación seudoobjetiva, pero "la precisión y el tecnicismo son soluciones ilusorias o respuestas parciales" (Gimeno 1997, 70) y degeneró en un pensamiento educativo que

está encuadrado en modos burocráticos de pensamiento, y nos inclinamos a pensar y a actuar instrumental y técnicamente dentro de la trama burocrática, sin combatirla de un modo crítico ni actuar positivamente para transformar-

la. Los sistemas burocráticos se nos presentan con pautas de pensamiento y acción difíciles de combatir y de cambiar (Kemmis 1998, 141).

Lo anterior, no implica que la artritis del currículo solo se presente en el área de movilidad pública, por el contrario, es una afección presentada en las articulaciones públicas y privadas, así como transversal a todos los niveles del sistema educativo. Esta artritis se manifiesta con un endurecimiento del poder de decisión curricular (ajeno a la contextualización curricular), la verticalidad de la organización, la centralización de la toma de decisiones, el poder excesivo de jefaturas y mandos medios, inflamados sistemas de control, papeleo y evidencias, organización por grados, distribución y clasificación de estudiantes, rígidos procedimientos de diseño curricular, por citar algunos ejemplos.

Un currículo con sus articulaciones rígidas en todos los niveles de decisión, diseño, implementación y evaluación no podría haber soportado el cambio a la virtualidad en una forma tan abrupta. El poco tiempo entre el surgimiento de la necesidad y la reacción curricular demostró, a todas luces, que el paciente sufrió un proceso de angustiosa agonía similar a la de los dinosaurios excepto que, al menos, los dinosaurios gozaron de mayor flexibilidad de reacción. 


\section{Las cirugías estéticas, problemas psiquiátricos y esteroides}

El paciente presenta evidentes cirugías estéticas que trataron de disimular su avanzada edad y sus males. En su cuerpo, se encuentran señas de decenas de reformas para liposucción de contenidos, aumento de perfiles, aumento de actividades didácticas seudoconstructivistas, implante de actividades evaluativas seudocualitativas; sin embargo, tanto para el sistema público como privado

la paradoja a la que ambos sistemas se encuentran abocados es la radical ineficacia de los cambios y reformas impuestos desde fuera y sin la voluntad y el convencimiento de los agentes involucrados. Los cambios así implantados o exigidos no suponen el incremento de la calidad de las prácticas ni el desarrollo individual e institucional, sino simplemente la modificación superficial de las formas, rutinas y lenguajes, que a la postre cumplen con el aforismo de Lampedusa de que todo cambie para que todo siga igual (Pérez 1998, 166).

Para un observador experto, las cirugías plásticas realizas por el currículo no hacen más que maximizar las contradicciones del sujeto en el marco de su misión en las sociedades democráticas modernas, mostrado en un amplio expediente de enfermedades psiquiátricas, como trastorno de ansiedad, para ser aceptado por el empresariado nacional y global, trastorno de pánico ante cualquier crítica disruptiva, trastorno obsesivo compulsivo por el control del cuerpo docente, fobia a la pedagogía crítica, esquizofrenia ante la aparición de las familias de educandos, narcisismo pedagógico, trastorno de dependencia a editoriales, trastorno alimenticio (atracones de modas seudo curriculares-pedagógicas) y bipolaridad.

La bipolaridad del currículo fue descrita con claridad por Santos (1999) y se manifiesta en que el sistema educativo es una institución de reclutamiento forzoso que pretende educar para la libertad, educar en y para la democracia, heterónoma que busca desarrollar autonomía, educar para los valores democráticos y para la vida, epistemológicamente jerárquica que persigue educar para la creatividad, el espíritu crítico y el pensamiento de la gente, es sexista pero procura educar para la igualdad entre los sexos, pretendidamente igualadora que mantiene mecanismos que favorecen el elitismo, busca la diversidad pero forma para competencias culturales comunes, cargada de imposiciones, que pretende educar para la participación, acrítica que pretende educar para la exigencia democrática, aparentemente neutral que esconde una profunda disputa ideológica. 
Aunado a las operaciones estéticas y las enfermedades psiquiátricas, el paciente muestra evidencia toxicológica de consumo de esteroides anabólicos probablemente para aumentar su masa muscular y resultar más atractivo para la sociedad-empresariado. Los esteroides hallados son denominados, en el bajo mundo pedagógico, como Competencias.

Debido a enfermedades descritas previamente, los esteroides de competencias también han sido consumidos por el currículo durante las dos últimas décadas, como posible cura algunas situaciones de salud; sin embargo, es evidente la generación de una adicción que afectó todo su cuerpo y una negación del origen de la droga. Las competencias, como bien describe Gimeno (2009), representan una forma de comprender la educación y al currículo en sí mismo, forjada en un origen de contexto de solicitud de cambios pedagógicos y un libre mercado que presiona por su agenda educativa; caracterizada por la pretensión de lograr rigor en la medición de logros (competencias), el impulso de la ruta europea de homologación, con una ambigüedad de significados y sobre cuáles son las necesarias, sin garantías de éxito a pesar del amplio apoyo supranacional, nacional y empresarial, generadora de problemas técnicos artificiales y como respuesta que omite el aporte de fuentes del saber que aún son necesarias y útiles.

No existe una evidencia de sobredosis por uso de la droga de competencias; sin embargo, esta autopsia debe dejar constancia de que el consumo de esta droga durante tanto tiempo pudo debilitar aún más al paciente, así como incrementar los efectos negativos de otras enfermedades aquí analizadas. Así mismo, debe reconocerse que esta droga, sumada al consumo de las drogas de moda de calidad y excelencia, provocan una negación de realidades mientras que quien las consume tiende a creer que "ya vivimos en un mundo donde hay igualdad de oportunidades, por tanto no tiene sentido hablar de clases sociales, racismo, sexismo, injusticias y desigualdades sociales y, mucho menos, relacionar estas dimensiones con el fracaso escolar" (Torres 2006, 29), lo cual, para el currículo, es claramente el paso previo al suicidio.

\section{Mala praxis}

Aunado a las causas de la muerte descritas en la presente autopsia, resulta necesario reflexionar sobre la mala praxis curricular de la que fue objeto este paciente. Las enfermedades encontradas, y otras latentes, eran tratables, pero los diferentes especialistas curriculares a los que acudió el paciente dieron diagnósticos erráticos, deficientes y hasta equivocados.

El poder tácito (autoridades públicas o privadas con control de la institución educativa) delegó en el Doctor Ministro-Secretario-Rector cuyos conocimientos en currículo fueron insuficientes. Su toma de decisiones se basó en políticas públicas, estados financieros, atención de grupos de presión, intereses corporativos o gremialistas, compromisos políticos y hasta criterios de interés subjetivo. 
La Doctora Investigadora Curricular con una experiencia centrada en procedimientos formales y un énfasis en técnicas de aprendizaje (que no eran ni técnicas ni de aprendizaje), examinó al paciente y le dictaminó acetaminofén para sus males. Es claro que las redes de discusión con otros doctores especialistas en lo curricular hubieran brindado visiones y experiencias adicionales para comprender la complejidad del paciente.

El Doctor Curricular Mando Medio, históricamente encargado de una oficina con poder de gestión, saturado de procesos, con una formación teórica debilitada, disminuido de poder frente a la toma de decisiones, vilipendiado por sus colegas de evaluación-acreditación y afectado por un énfasis en la acción más que en la reflexión; atendió a este paciente con procedimientos desactualizados, mezclando técnicas-recetas incompatibles y con una rapidez que diluyó las posibilidades de análisis de fondo de los trastornos.

Finalmente, y ante la desesperación por su sobrevivencia, el paciente acudió a prácticas de dudosa validez médica. Homeopatía de Modas Curriculares en la cual se disolvían decenas de teorías (desde complejidad hasta humanismo) en grandes cantidades de líquido para obtener una milésima de fracción del producto original; accedió a mejoras del Chacra Curricular para aliviar sus males espirituales; usó Acupuntura Curricular, entendida como una acción dirigida a aspectos específicos del diseño curricular o las estructuras curriculares, cuya implementación generaría cambios en todo el currículo e incluso acudió a la aromaterapia de fragancias teóricas de otras disciplinas.

Las malas praxis condujeron al paciente al dilema popular de "entre todos lo mataban y él sólo se moría", debilitado, angustiado y sin acceso a un sistema de salud pedagógica fortalecida, el paciente agonizó hasta colapsar por completo.

\section{Conclusión}

En el año 2020, el currículo ingresa a sala de urgencias pedagógicas con un traumatismo severo por el choque con la pandemia del COVID-19 y la necesidad de la virtualidad. Se le declara fallecido en el sétimo mes de 2020 , después de semanas en cuidados intensivos, la autopsia encuentra como posibles causas de muerte el elemento ambiental, el accidente cerebrocurricular, el infarto al miocardio (aprendizaje), el cáncer linfático (con especial atención de los linfocitos docentes), la cirrosis evaluativa, la artritis curricular, cirugías estéticas, problemas psiquiátricos, el uso de esteroides pedagógicos, la mala praxis y el factor ambiental.

No es la primera vez que el currículo es diagnosticado como grave o moribundo, desde la primera declaratoria de Joseph Schwab, en 1969, investigadores e investigadoras curriculares han anunciado su muerte, anuncios al cual se suma esta autopsia: el currículo ha muerto.

Lo anterior no debe alegrar a críticos del paciente ni entristecer a sus acérrimos defensores; en las áreas pedagógicas, existe la certeza de que hay 
muertos que gozan de buena salud y el currículo ha demostrado que puede resucitar a los tres días de sus reformas. Una y otra vez, grupos de presión, inercia pedagógica y hasta casualidades, le han permitido volver a tener vida a pesar de su maltrecha condición de salud. Pero en esta ocasión, su muerte (aunque momentánea) evidencia un hecho inobjetable: la presencialidad mantenía con vida el currículo y el traslado a la virtualidad fue mucho más de lo que podría soportar.

La presencialidad, específicamente la contextualización curricular, es un espacio que involucra la interacción de docentes y estudiantes donde surgen lenguajes, emociones, asociaciones, confrontaciones y uniones, es un espacio dinámico, vivo y en constante transformación que permite crear experiencias de aprendizaje más allá de las pretendidas, autorizadas o dictadas por el programa del curso. En ese espacio, el currículo mantiene su última trinchera en la lucha por la sobrevivencia, pertinencia y significancia.

El currículo ha muerto. Tal vez, al igual que en otras ocasiones, podrá resucitar, pero lo hará con las mismas enfermedades; será más débil, viejo y estará más cansado, por lo cual será necesario preguntarnos ¿cuáles serán las medidas necesarias para refundar su estado de salud?, y ¿será posible mejorar su estado de salud?

Al respecto de estos últimos cuestionamientos, es posible construir alternativas curriculares desde sectores académicos y profesionales que promuevan el surgimiento de un nuevo currículo. Para tal fin, resulta necesaria la construcción de espacios de investigación y reflexión curricular, generación y sistematización de experiencias en innovación del diseño del currículo, cambios en las funciones y concepción misma de la docencia, nuevo papel (protagónico) de estudiantes y familias en la toma de decisiones curriculares-evaluativas, transformaciones significativas de la contextualización curricular y la implementación de un sistema de evaluación procesual con premisas cualitativas; todo esto a partir de premisas para el diseño e implementación curricular como lo son la inclusión, democratización, equidad, flexibilidad, diálogo y colectividad.

Para alcanzar este nuevo currículo, o al menos para mejorar las condiciones de vida del actual sujeto curricular, se requiere una participación proactiva de las universidades o centros de educación pedagógica superior, ministerios o secretarías de educación pública, instituciones de supervisión o regulación de la educación, institución de acreditación, organizaciones de familias, organizaciones no gubernamentales, sociedad civil y productiva. Es decir, las responsabilidades para obtener un currículo acorde a las realidades del siglo $\mathrm{XXI}$ requieren la confluencia de diversas instituciones u organizaciones sumados al papel curricular de mandos medios, docentes, estudiantes y personas administradoras de centros educativos.

Por último, se requiere indicar que la pertinencia y relevancia del currículo estará determinada por el uso - o no uso- de la pedagogía crítica como herramienta para el cuestionamiento del proceso y de los intereses, explícitos o 
no, de grupos o personas con respecto a la razón de ser del proceso educativo y del currículo como producto cultural en el marco de proyectos hegemónicos y de resistencia.

\section{Referencias}

Abrahamson, Stephen. 1978. Deseases of the curriculum. Recuperado de: https://edu.umsu.ac.ir/uploads/curr_29984.PDF

Apple, Michael. 1999. "La política del saber oficial: ¿tiene sentido un currículum nacional?" En: Manzano, Pablo. (coord.). Volver a pensar la educación. (Vol. I). Madrid: Morata.

Apple, Michael. 1996a. El conocimiento oficial. España: Paidós.

Apple, Michael. 1996b. Política Cultural y Educación. España: Paidós.

Apple, Michael. 1997. Educación y poder. España: Paidós.

Freire, Paulo. 2001. Política y Educación. México, D. F: Siglo XXI.

Gimeno, José. 1997. La pedagogía por objetivos: Obsesión por la eficiencia. España: Morata.

Gimeno, José. 2009. "Diez tesis sobre la aparente utilidad de las competencias en educación". En Gimeno, José (comp.), Educar por competencias ¿Qué hay de nuevo? (15-58). Madrid: Morata.

Gimeno, José. 2010a. “¿Qué significa el currículum?” En José Gimeno (comp.), Saberes e incertidumbres sobre el currículum (21-44). Madrid: Morata.

Giroux, Henry. 2006. La escuela y la lucha por la ciudadanía. Pedagogía crítica de la época moderna. México, D. F.: Siglo XXI.

Pérez, Ángel. 1998. La cultura escolar en la sociedad neoliberal. Madrid: Morata.

Kemmis, Stephen. 1998. El currículum: más allá de la teoría de la reproducción. España: Morata.

Santos, Miguel. 1995. La evaluación: un proceso de diálogo, comprensión y mejora. Málaga: Aljibe.

Santos, Miguel. 1999. "Democracia escolar o el problema de la nieve frita" (128-141). En: Congreso Internacional de Didáctica. Volver a pensar la educación (Vol. I), La Coruña, PAIDEA.

Stenhouse, Lawrence. 2003. Investigación y desarrollo del currículum. Madrid: Morata.

Taba, Hilda. 1974. Elaboración del Currículo. Teoría y Práctica. Buenos Aires: Troquel. 
Tyler, Ralph. 1973. Principios básicos del currículum. Buenos Aires: Troquel.

Torres, Jurjo. 2006. La desmotivación del profesorado. Madrid: Morata.

Torres, Jurjo. 2007. Educación en tiempos de neoliberalismo. Morata. Madrid, España

Torres, Jurjo. 1998. El currículum oculto. Sexta Edición. España: Morata.

Toruño, César. 2020. "El currículum en el contexto costarricense: propuesta de definiciones para su conceptualización". Revista Ensayos Pedagógicos, 15(1): 39-59. Recuperado de: https://doi.org/10.15359/rep.15-1.2

Toruño Arguedas, César. 2020. "Marcos conceptuales para un currículo crítico: una propuesta desde la pedagogía crítica brasileña, española y estadounidense". Revista Actualidades Investigativas en Educación, 20(1): 1-27Recuperado de: Doi 10.15517/aie.v20i1.40124

Toruño, César. 2010. "Los fundamentos curriculares de la ciudadanía en un Estado Neoliberal: el caso del sistema educativo costarricense". Actualidades Investigativas en Educación, 10 (2): 1-25. Recuperado a partir de https://revistas.ucr.ac.cr/index.php/aie/article/view/10132 